\title{
Urdimento
}

Revista de Estudos em Artes Cênicas E-ISSN: 2358.6958

\section{O exercício da amorosidade no trabalho criador da/do artista da cena}

Claudia Mele

\section{Para citar este artigo:}

MELE, Claudia. O exercício da amorosidade no trabalho criador da/do artista da cena. Urdimento,

Florianópolis, v. 1, n. 40, mar./abr. 2021.

do) DOI: http:/dx.doi.org/10.5965/1414573101402021e0103

Este artigo passou pelo Plagiarism Detection Software | iThenticate 
Claudia Mele ${ }^{1}$

\begin{abstract}
Resumo
O artigo propõe uma reflexão sobre como o exercício da amorosidade pode auxiliar na transformação de si, no entendimento da importância do trabalho colaborativo e na ampliação das possibilidades criativas na prática da/o atriz/ator. A pesquisadora, professora de disciplinas corporais em faculdades de artes cênicas, observou uma mudança significativa nas relações entre as/os estudantes, dentro e fora da sala de aula, após a realização de práticas através do estudo da teoria milenar hindu do sistema de chakras, com enfoque no chakra do coração. São apresentadas sugestões de exercícios, citações de percepções das/dos alunas/os e reflexões a respeito das práticas da amorosidade.
\end{abstract}

Palavras-chave: Amorosidade. Ator. Chakras. Pedagogia.

The exercise of lovingness in the creative work of the artist of the scene

\begin{abstract}
This article proposes a reflection on how the exercise of lovingness can help in transforming oneself, understanding the importance of collaborative work and expanding the creative possibilities in the actor's work. The researcher, teacher of body disciplines in theater colleges, noticed that there is a significant change in the relationships between students, inside and outside the classroom after performing practices through the study of milenar hindu theory of chakra system, focusing on the heart chakra. Will be presented suggestions of exercises, quotes from students' perceptions and reflections from the practices of lovingness.
\end{abstract}

Keywords: Amorosity. Actor. Chakras. Pedagogy.

${ }^{1}$ Atriz, diretora, autora e preparadora corporal. Doutoranda e Mestre em Artes Cênicas (2013) pela UNIRIO. Professora da Faculdade CAL de Artes Cênicas, da Faculdade Cesgranrio de Teatro e da Pós-Graduação em Preparação Corporal nas Artes Cênicas (FAV). Na Universidade Santa Úrsula, é professora dos cursos de Arquitetura e Urbanismo, Psicologia e Direito em disciplinas com enfoque na expressão vocal e corporal e na criatividade. meleclaudia@gmail.com

(3ttp://lattes.cnpa.br/4560053088812084 
El ejercicio del amor en el trabajo creador del/a artista de la escena

\section{Resumen}

Este artículo propone una reflexión sobre cómo el ejercicio del amor puede ayudar en la transformación de símismo, en la comprensión de la importancia del trabajo colaborativo y en la ampliación de posibilidades creativas en la práctica del/a actor/actriz. La autora, profesora de disciplinas corporales en universidades de artes escénicas, señaló que hay un cambio significativo en las relaciones entre alumnas/os después de realizar prácticas relativas al estudio de la teoría milenaria hindú del sistema de chakras con un enfoque en el chakra del corazón. También se presentan sugerencias de ejercicios, citas textuales de la percepción de los/las estudiantes y reflexiones sobre las prácticas amorosas.

Palabras clave: Amor. Actor. Chakras. Pedagogía. 
O nível de consciência do chakra do coração percebe o mundo como uma complexa rede de relações unidas pela força do amor (Judith, 2010, p.235).

Em 2012 vivi uma experiência singular quando estive em Takayama, no Japão, para participar de um seminário de imposição da mão². No final da cerimônia fui ao altar para receber das mãos do grande mestre, Oshienushisama, a medalha sagrada. Ao colocá-la no pescoço senti os meus corpos sutis vibrarem intensamente, apesar do meu corpo físico permanecer parado. As vibrações faziam um percurso ascendente e descendente, indo da cabeça aos pés e viceversa. Então, fiz uma reverência ao mestre e enquanto voltava ao meu lugar, no grande templo, as vibrações se intensificaram. Como uma explosão, todo o meu corpo se expandiu rapidamente, perdi totalmente o contorno, minha pele se tornou espaço. Ao andar não sentia o chão, parecia que eu caminhava sobre nuvens. Naquele momento, pude observar os vários rostos, a maioria de japoneses que não conhecia, sentindo um profundo amor por eles, um amor como nunca havia experienciado, amor incondicional. Tive a sensação que o tempo havia parado, estava fora do tempo e do espaço e a única coisa que podia sentir era o amor. Após esta experiência, passei três meses muito expandida, como se eu estivesse vibrando em outra frequência, em outra estação de rádio, diferente da realidade cotidiana a que estamos habituados/as. Na verdade, fiquei oscilando entre estados muito sutis e outros mais comuns de consciência. Esta experiência me fez entender no corpo o que é vibrar em diferentes dimensões e, principalmente, me trouxe a consciência que o objetivo maior da vida sempre é e será o amor.

Nesta pesquisa, proponho a acepção de amor incondicional relacionada à compaixão, vínculo e empatia por nós mesmos/as e por todos os seres, inclusive por pessoas desconhecidas, ou com as quais não temos afinidades. Investigo a

2 Técnica espiritualista, da Sukyo Mahikari, que pratico desde 2000. A prática tem como objetivo promover a paz e a harmonia na sociedade por meio da purificação espiritual, realizada pela prática de imposição da mão e do exercício diário dos princípios universais de gratidão, aceitação e humildade em todos os aspectos da vida. 
amorosidade como uma prática que possibilita nos tornarmos colaboradores da harmonia coletiva.

Quando viajei ao Japão, estava escrevendo minha dissertação de mestrado e pesquisando os estados de presença da/o atriz/ator. A experiência descrita anteriormente confirmou que eu deveria continuar na mesma direção. Portanto, a pesquisa de doutorado seguiu as mesmas linhas de investigação: a multidimensionalidade do corpo; práticas corporais e vocais que podem ampliar a percepção; a composição de metodologias que buscam o autoconhecimento, a mudança de padrões comportamentais, a abertura para estados criativos e a transformação de si. A base dos processos metodológicos parte da investigação teórico/prática dos estudos milenares hindus sobre o sistema de chakras e dos corpos sutis ${ }^{3}$, contido na filosofia do Yoga, para vivenciar os diferentes níveis de consciência. Atrevo-me a essa apropriação respaldada nos muitos anos de trabalho como atriz e professora de técnicas corporais para a/o atriz/ator. Além disso, as práticas espirituais com as quais estou envolvida têm influenciado meu trabalho como artista e pedagoga, pois possibilitam a observação e o contato com esses métodos e experiências.

Segundo Stanislávski (Vássina, Labaki, 2015), a/o atriz/ator deve ter plena consciência de sua natureza intelectual, física, emocional e espiritual. O trabalho sobre si mesma/o, uma das vertentes da prática do diretor russo, é importante para que a/o artista possa transmitir suas ideias e sentimentos usando as próprias emoções, sensações, instintos e experiências pessoais. O trabalho sobre si é a condição básica para a atuação. Em uma das disciplinas que leciono, na Faculdade Cal de Artes Cênicas e na Faculdade Cesgranrio de Teatro ${ }^{4}$, compus uma grade de exercícios a partir do modelo estrutural do sistema de chakras e corpos sutis para que a/o aluna/o possa desenvolver o trabalho sobre si. O conjunto de práticas é dividido em dois módulos: o primeiro tem como objetivo principal o

\footnotetext{
${ }^{3}$ Os corpos sutis são níveis de consciência em diferentes frequências vibratórias que se comunicam através de centros energéticos distribuídos ao longo do eixo central do corpo: os sete chakras principais. Estes centros energéticos são responsáveis pela recepção, assimilação e transmissão de energia vital entre os corpos sutis e o ambiente.

${ }^{4}$ Também lecionei esta disciplina no curso de Bacharelado em Teatro da UNIRIO, no segundo semestre de 2019, como professora substituta.
} 
autoconhecimento; o segundo tem uma abordagem mais técnica, visando à criação de personagens, ao estudo de estados, gestos e à criação de dramaturgia corporal e textual. No primeiro módulo, não estou preocupada com o desempenho técnico ou com resultados expressivos (apesar de acontecerem). Toda a atenção está voltada para o processo de autoconhecimento, proporcionando às/aos mesmas/as contato com seus bloqueios, limites e potências. Cada aula tem como foco um determinado chakra. Neste artigo apresentarei alguns exercícios, reflexões e depoimentos de alunas/os sobre às vivências do chakra cardíaco.

O chakra do coração, anahata, é o centro do amor, equilíbrio, afinidade, ar, respiração e cura. Encontrar o amor do quarto chakra é transcender o ego, indo em direção a algo mais sutil e universal. Seu símbolo são dois triângulos, um aponta para baixo e outro aponta para cima, representam a descida do espírito ao corpo e a ascensão da matéria orientada ao espírito. Consequentemente, ele é o centro dos movimentos ascendentes e descendentes de energia, fazendo a ligação entre os chakras ligados à materialidade do corpo, às emoções e ao pensamento e os chakras espirituais relacionados à intuição, à criatividade e à espiritualidade. Por ser a ponte entre os planos físico e espiritual atua na interpenetração equilibrada do masculino e do feminino. Core significa âmago, núcleo e centro, portanto o anahata é o coração de todo o sistema.

Segundo os Upanishads5, Brahman reside na caverna do coração dos seres conscientes na ponte entre o mundo físico e o mundo espiritual. Há beleza em percebermos que o divino reside no coração, centro onde se metaboliza o amor. Para os hindus a centelha divina que nos habita se localiza nos olhos e no coração, respectivamente o chakra ajna, conhecido como terceiro olho, e o anahata. Bárbara Brennan (2018), cientista e curadora, afirma que o amor incondicional flui quando existe conexão entre os dois centros. Em outros termos, vivenciamos o amor incondicional ao combinarmos a experiência de amor por nossos semelhantes (anahata) com o amor do êxtase espiritual que ultrapassa a realidade física da

5 Upanishads "são parte das escrituras Shruti hindus, que discutem religião e que são consideradas pela maioria das escolas do hinduísmo como instruções religiosas. Contêm também transcrições de vários debates espirituais, e 12 de seus 123 livros são considerados básicos por todos os hinduístas". Disponível em: https://pt.wikipedia.org/wiki/Upanixade . Acesso em: 10 out. 2020. 
presente existência (ajna).

Há vinte anos foi criado um campo de pesquisa cujo objetivo é investigar a relação do coração com o cérebro, a neurocardiologia ${ }^{6}$. O Heartmath Institute ${ }^{7}$ tem realizado pesquisas amplas nesta área e constatou que o coração tem seu próprio sistema nervoso constituído por uma rede de neurônios sofisticada, chamada de "cérebro do coração". Os cientistas têm observado que o coração envia mais sinais para o cérebro do que o contrário. Os sinais cardíacos têm um efeito significativo sobre a função cerebral, influenciando o processamento emocional, bem como as faculdades cognitivas superiores. A rede do coração contém mais de 40 mil neurônios que o auxiliam a detectar e processar informações, tomar decisões e até mesmo aprender e criar memória. Outro dado relevante e muito esclarecedor: o coração também é uma glândula hormonal que fabrica e secreta inúmeros hormônios e neurotransmissores, entre os primeiros está a oxitocina, conhecida como "amor" ou "hormônio de ligação".

Quando o padrão rítmico do batimento cardíaco está suave e organizado, ele sincroniza o ritmo do cérebro, do sistema nervoso, dos órgãos internos e das glândulas, permitindo que todos entrem em harmonia - os cientistas o chamam de “ritmo coerente". Portanto, aprender a gerar maior coerência no ritmo cardíaco, mantendo as emoções positivas, não apenas beneficia todo o corpo, mas também afeta profundamente a maneira como percebemos, pensamos, sentimos e atuamos no mundo.

Segundo Joseph Chilton Pearce (2004), o coração é o primeiro órgão a ser formado no feto. O EEG, exame que mede as ondas cerebrais, mostra que os sinais eletromagnéticos do coração são muito mais fortes do que as ondas cerebrais. O espectro de frequência do coração pode irradiar-se a três metros do corpo físico.

\footnotetext{
6 A Neurocardiologia é o novo seguimento da medicina que estuda as interações dos sistemas nervoso e cardiovascular. Há cerca de vinte anos, na era pós-transplantes de órgãos, iniciaram-se estudos que demonstraram que indivíduos submetidos a transplantes de coração-pulmão passaram a apresentar mudanças em seus comportamentos e, em certos casos, recebiam "informações" que eram dos próprios doadores. Disponível em: http://www.esteta.com.br/noticia-imprimir.php?intNotID=27027. Acesso em: 01 out. 2020.

${ }^{7}$ Informações contidas no site do Heartmath Institute. Disponível em: https://www.heartmath.com /science/. Acesso em: 05 set. 2020 .
} 
O autor afirma que a frequência eletromagnética do coração produz arcos para fora do coração, como anéis de energia, e que o eixo destes se estendem do assoalho pélvico ao topo do cabeça, ou seja, abrange todos os chakras principais. Pearce acredita que quando nos desconectamos da sabedoria inata do amor, focando apenas nos pensamentos, o intelecto refletido no ego assume o controle e opera independentemente do coração. Desta maneira, nos voltamos para uma mentalidade de sobrevivência baseada no medo, ganância, poder e controle. À medida que nos propomos a realizar uma revolução tranquila, com o objetivo de viver a partir coração, começamos a ver os reflexos em nossas vidas e em nosso ambiente. Pearce acredita que esta é a chave para criarmos uma mudança de paz, harmonia e equilíbrio no mundo.

Para bell hooks $(2006)^{8}$, uma cultura de dominação é anti-amor. A artista e teórica destaca a falta de atenção ao amor em círculos políticos progressistas, visto que esta ausência surge da ênfase nas preocupações materiais e na falha coletiva em reconhecer as necessidades do espírito. Falar de amor nestes espaços é considerado ingênuo. Hooks defende o amor no centro das ações de oposição aos valores predominantes de dominação da nossa cultura, ressaltando que frequentemente reagimos apenas quando nossos interesses são ameaçados. Consequentemente, precisamos de uma ética baseada no amor para desenvolvermos empatia e compaixão; desta forma, voltamos nossa atenção e preocupação às práticas de dominação sobre as/os outra/os. A autora entende que o amor é um ato de vontade, uma intenção, uma ação, que implica em uma escolha. Esta requer uma tomada de consciência de nós mesmas/os para percebermos o nosso auto-ódio, a baixa autoestima e os pensamentos supremacistas brancos. Quando nos conscientizamos, entramos em processo de cura, pois instintivamente possuímos os recursos interiores para enfrentar nossas dores. Portanto, a ética do amor enfatiza a importância do serviço a outrem. A hierarquização do sistema patriarcal desvaloriza tarefas ou trabalhos relacionados à categoria de "serviço", contudo, o mesmo nos capacita à compaixão e aprofunda 
nossa percepção da vida e das relações.

O psiquiatra e pesquisador David Hawkins (2002) observa que o amor não toma partido, pois está acima da ideia de separação. Ele atribui uma possível escala de valores da consciência baseada nas emoções, relacionando-as a números. Durante mais de vinte anos, o médico realizou testes musculares (cinesiologia ${ }^{9}$ em grupos de pessoas para investigar como os sentimentos as afetam. Logo percebeu que teria que utilizar logaritmos ${ }^{10} \mathrm{em}$ vez de números simples, porque o poder da consciência nos níveis mais sutis é muito vasto quando comparado aos mais densos. Como comparativo, na escala de Hawkins a potência do amor é 500, enquanto da raiva (ira) é 150. O primeiro vibra em uma faixa de frequência energética muito mais sutil, interferindo na consciência da Terra de uma forma mais contundente que a ira. O pesquisador conclui que uma única pessoa vibrando na faixa do amor pode afetar a Terra mais do que 700 mil indivíduos que vibram na ira.

Minhas práticas de vida e arte visam constantemente à conexão e à abertura do coração para o amor. Acredito que, no momento em que escrevo este artigo, no oitavo mês de pandemia do coronavírus, somos convidadas/os diariamente a olhar para nós mesmas/os. Quando conseguimos olhar com amorosidade, o processo se torna realmente revolucionário e transformador. Meu encontro com a amorosidade se estabelece em um aprendizado de muita delicadeza. Mas, às vezes, me julgo por não conseguir me abrir com mais facilidade. O bloqueio no coração vem do medo da dor, que pode ser dor do abandono, dor de não ser aceita/o, ou dor de não ser amada/o. Ao entendermos com o coração a causa daquela dor, a transformamos e nos sentimos gratas/os e amorosas/os.

\footnotetext{
${ }^{9}$ Cinesiologia é o estudo científico do movimento do corpo humano, abordando os princípios e mecanismos fisiológicos, biomecânicos e psicológicos do movimento. Este estudo reconhece que existem fluxos de energia dentro do corpo que se relacionam não apenas com os músculos, mas com todos os tecidos e órgãos que fazem do corpo um ser vivo e sensível. Com a Cinesiologia, as mentes conscientes das pessoas são isoladas para que se recebam respostas claras diretamente das suas mentes subconscientes (Hawkins, 2002).

${ }^{10}$ Quando se utiliza um sistema logarítmico de base-dez, o número 4 não é apenas duas vezes maior que o número 2. O logaritmo de 4 é 10.000 contra o valor do logaritmo de 2 que é só 100. Um nível de consciência de 300 não é apenas duas vezes maior que o nível de 150, o nível de 300 significa 10 elevado a 300; ou seja, o número 1 com 300 zeros depois dele.
} 
O chakra do coração está provocando uma revolução em minha vida. Cada aula em torno deste centro de energia amorosa me transforma um pouco mais. Ao longo do desenvolvimento deste trabalho, os encontros voltaram-se progressivamente para o autoconhecimento, sobrepujando intenções técnicas e estéticas. Isto se deve às transformações das/os alunas/os durante os processos, de acordo com as minhas percepções à medida que ministrava as aulas do anahata. Observei, simultaneamente, mudanças em mim, em alguns indivíduos específicos e até mesmo em turmas inteiras.

O chakra do coração até agora foi o que senti de maneira mais forte repercutir em mim, nas minhas sensações e no meu comportamento. Senti essa força amorosa se expandir e acredito que cada um que tenha saído verdadeiramente tocado pela aula tenha carregado consigo essa energia. Me senti mais paciente, mais amorosa, mais atenta, mais entregue, mais dedicada, mais empenhada, mais grata, mais sensível. Sempre agradeço muito, mas dessa vez minhas orações se ampliaram e minhas demonstrações de amor e gratidão às pessoas também (Marcela) $)^{11}$.

Se tem algo que eu pude constatar nessa aula foi que o amor realmente transforma. E não foi só porque a minha relação com algumas pessoas da turma mudou para melhor, e sim porque o grupo como um todo está muito mais unido (Jéssica).

Descrevo abaixo alguns exercícios que experimentamos nas aulas do chakra cardíaco.

\section{Meditação da bondade amorosa}

Sentar com apoio nos ísquios. Observar a respiração sem alterá-la. Levar a atenção para o centro do peito e através da respiração imaginar uma luz saindo deste ponto. A cada inspiração visualizar que está ampliando a luz do coração. A cada expiração expandir a luz de bondade amorosa para baixo e

\footnotetext{
${ }^{11}$ Relatos de alunas/os após a experiência em aulas sobre o chakra do coração no período pré-pandemia. Durante o artigo citarei relatos de diferentes turmas da Faculdade Cal de Artes Cênicas, da Faculdade Cesgranrio de Teatro e do curso de teatro da UNIRIO, todas localizadas no Rio de Janeiro. Alguns nomes são fictícios e outros foram autorizados pelas/os próprias/os.
} 
para cima, pelo eixo central do corpo, irradiando para todas as células do corpo, mente e espírito. Mentalizar: "Aquele que ama a si próprio nunca causará mal ao outro".

Trazer à mente uma pessoa que goste muito. Relembrar suas qualidades, enviando-lhe amor. A cada expiração, através do coração, emanar uma luz de generosidade e bondade amorosa para a pessoa.

Trazer à mente uma pessoa conhecida que não tenha nenhuma relação mais forte com você, nenhuma sensação especial de proximidade. Repetir o movimento anterior de radiação de amor, desejando que ela seja feliz.

Realizar o mesmo processo com uma pessoa que você tenha dificuldades de se relacionar, que irrite você. Imaginar que ela está tentando ser feliz a seu modo. Procurar perceber o seu ponto de vista. Emanar amor para ela. Realizar o mesmo processo das duas meditações anteriores e perceber o que sente. Procurar fazer com todo o amor, do fundo do coração.

Esta meditação foi proposta por Allan Wallace em seu livro Felicidade Genuína (2015). Segundo Wallace, a bondade amorosa é a primeira das quatro qualidades imensuráveis que precisamos cultivar na vida. O autor a define como "uma aspiração sincera de que outros possam experenciar a felicidade e as fontes de felicidade" (s.n.. ${ }^{12}$. As outras qualidades são: compaixão, alegria empática e equanimidade. Cada uma é um elemento vital para a felicidade genuína: a compaixão é desejo que as pessoas fiquem livres do sofrimento; a alegria empática é a consciência da virtude e da alegria de outras pessoas; e a equanimidade é o reconhecimento de que todos estão, assim como nós, em busca da felicidade, desejando estar livres do sofrimento.

Wallace descreve um comentário do Dalai Lama sobre mestres budistas que baseavam sua prática de meditação centrada na atenção plena ${ }^{13}$. Embora

${ }^{12}$ Livro lido no Kindle. Por este motivo, não há numeração (s.n.).

${ }^{13}$ A atenção plena é a habilidade de focar continuamente a atenção em um objeto escolhido, sem distração, que pode ser uma parte do corpo, uma sensação, um pensamento ou uma visualização. A atenção plena é a qualidade de permanecer no aqui e agora (Wallace, 2015). 
demonstrassem profunda calma e equanimidade, percebia neles "uma qualidade de austeridade e falta de alegria, sem calor e empatia aparentes pelos outros. Sabedoria sem compaixão é aprisionamento" (Wallace, 2015, s.n.). Por este motivo, o mestre tibetano acredita que o cultivo das qualidades saudáveis do coração e sua expressão na conduta cotidiana são tão importantes quanto as práticas de atenção plena.

Após a meditação da bondade amorosa, eu aplico um exercício de sensibilização da cintura escapular e do tórax, sede do coração e dos pulmões, ambos regidos pelo chakra cardíaco. A atividade tem a potência de sensibilizar e "amolecer" a estrutura torácica, proponho a mesma com o intuito de abrir o anahata.

O exercício em dupla, em que um distensionava o corpo do outro, foi interessante para mim, porque ao perceber as tensões do meu colega eu também reconheci as minhas. Foi para mim, acima de tudo, um exercício de empatia e confiança no outro (Daniel).

\section{Sensibilização da cintura escapular e tórax}

Formar duplas. Sentadas/os. A/O aluna/o A de costas para a/o aluna/o B. Os dois fecham os olhos e observam a respiração sem alterar o ritmo. B abre os olhos e toca a escápula direita de A, procurando perceber os contornos do osso. Massageia a musculatura entre a coluna e a escápula.

B coloca o braço direito de A dobrado com o antebraço tocando as costas de A. Desta forma, a escápula é ressaltada e é possível, dependendo da soltura da musculatura, enfiar os dedos por baixo da escápula. Enquanto a mão direita de B puxa o ombro direito de A e faz movimentos circulares com este, a mão esquerda de B tenta aprofundar os dedos por baixo da escápula de A.

Após retirar o braço de A das costas, B começa a deslizar os dedos nos diversos espaços entre as costelas de A, desde a coluna vertebral até o osso esterno do lado direito do corpo. A observa a sua respiração, comparando os dois lados. 
Depois B desliza as mãos sobre o lado direito da caixa torácica de A a partir da escápula, seguindo pelo braço até as pontas dos dedos.

Por fim, B se afasta e A observa as diferenças entre os lados direito e esquerdo. B, então, repete todo o percurso, focando no lado esquerdo. A e B trocam as funções.

Entre as duas escápulas se situa o vórtex de energia do coração. O anahata, assim como o segundo, o terceiro, o quinto e o sexto chakras, apresenta abertura tanto na parte anterior como na posterior do corpo. A região estre as escápulas costuma ser bem presa, muitas vezes com a musculatura aderida à escápula, limitando o movimento. Se o chakra está bloqueado, esta região costuma estar rígida e dolorida, assim como a região do esterno. Massagear o espaço entre as escápulas vai auxiliar no desbloqueio energético desta região.

Deslizar os dedos entre as costelas contribui para a consciência da musculatura intercostal. Com o fortalecimento desta musculatura a respiração se abre, pois as costelas ganham maior amplitude. Importante destacar que os dedos apenas tocam suavemente a pele, trazendo a sensação de ampliação da caixa torácica de forma leve. O toque sensibiliza a musculatura intercostal, auxiliando na sua soltura. Estes movimentos contribuem para uma inspiração mais profunda. O deslizar também auxilia no livre fluxo do ar que entra e sai dos pulmões.

A função do chakra cardíaco é a respiração, cuja a ação primordial é a distribuição de prana ${ }^{14}$ entre os chakras. Atividade fundamental para o equilíbrio de todo o sistema. O elemento do anahata é o ar. Este representa a leveza, a simplicidade e a suavidade. Quando nos sentimos envoltos em muito amor, a sensação é que caminhamos no ar, exatamente a sensação que tive quando estava no templo japonês. Talvez a expressão "caminhar nas nuvens" suceda da vivência de amorosidade a partir do chakra cardíaco. Ao deslizar as pontas dos dedos entre as costelas estamos estimulando, gentilmente, que as costelas se abram e convidem o ar a entrar. A respiração é uma das principais chaves para a abertura

${ }^{14}$ Prana é o princípio ativo da vida - Força Vital, se preferir. É encontrado em todas as formas de vida (Ramacharaka, 1904, p. 151). 
do chakra cardíaco. Ressalto que nestes tempos de pandemia, exercícios respiratórios auxiliam muito na constituição saudável dos pulmões, assim como todos os exercícios que estimulam a amorosidade.

O último movimento, deslizar as mãos sobre o corpo da/o outra/o desde a caixa torácica e as escápulas até as pontas dos dedos da mão, ajuda a dar contorno a toda a região trabalhada. Estimula a percepção de que os braços são uma extensão das escápulas e de toda a região torácica.

Começamos trabalhando com "as massagens" na região do chakra. Lembro que foi um misto de dor, com relaxamento e com uma sensação diferente. Falo diferente, porque não é uma sensação de felicidade ou de tristeza, mas de vontade de chorar. Isso foi mais na hora do toque na parte da frente do corpo, entre os peitos. O momento da massagem da parte de trás, na hora de abrir as escápulas, abrir "nossas asas", foi interessante também (Luiza).

\section{Mobilização da cintura escapular e tórax}

A e B de frente uma/um para a/o outra/o, em pé e próximos. B bate de leve com a ponta dos dedos no osso esterno de A, depois muda para movimentos circulares com leve pressão na mesma região. Quando inicia a música, A afetado pelo estímulo tátil de B se move a partir desta parte do corpo. Em seguida, B estimula através do toque diferentes partes da caixa torácica, cintura escapular e braços de A que continua respondendo com movimentos fluentes. Os dois permanecem em contato físico se locomovendo pelo espaço. Aos poucos o estímulo tátil vai diminuindo. Enquanto B não tocar outra parte, A se move a partir da liderança da última região estimulada. Depois trocam de função.

A massagem na região do esterno começa bem suave e aos poucos o estímulo vai provocando o movimento e a soltura da coluna dorsal e da caixa torácica. A musculatura da região do osso esterno costuma ser bem dolorida, atrás do mesmo se localiza a glândula timo. Esta desempenha importante papel no 
sistema linfóide do organismo, capacitando a resposta imunológica. Ao estimular a região do esterno por meio de toques ritmados e pressões, o sistema imunológico é ativado através do chakra do coração. Hawkins (2002) aplicava a seguinte ação quando seus pacientes estavam com energia baixa: primeiro ele golpeava ritmicamente e com leveza o osso esterno com o punho bem apertado, simultaneamente, pedia que os pacientes pensassem que eram muito amados. Isso fazia com que suas energias mudassem rapidamente para uma vibração mais sutil. Com a mobilização da região através do estímulo do esterno, o chakra do coração é convidado a se abrir aos poucos, sutilizando a energia e liberando o fluxo de movimento.

Tocar todo o osso esterno também foi fundamental para trabalhar, posteriormente, nos giros de peito. Não sabia que esse osso era tão extenso e que atrelado a pensamentos positivos era capaz de melhorar tanto o humor. Testei isso diariamente durante a semana e foi bastante efetivo. A dança em dupla foi linda de fazer. Em um primeiro momento me senti, de fato, sendo manipulado por alguém, mas meu corpo reagia de forma a se libertar disso. Era como se ele não suportasse o fato de ficar aprisionado a um estímulo externo e fosse expandindo aos poucos. Foi uma sensação maravilhosa, porque ele dançava sozinho, sem qualquer racionalização de movimento (Lucas).

Após a sensibilização do esterno, a pessoa que manipula começa a estimular outras regiões da caixa torácica e da cintura escapular da/o parceira/o. Quanto mais fluentes forem os movimentos, maior será o vórtex de energia mobilizado e quanto mais expandido for o chakra, maior será o fluxo de movimentos. O corpo estimulado entra em espirais de ações e a dupla baila pela sala, sendo um a/o condutora/condutor e a/o outra/o a/o conduzida/o. 
Figura 1 - Mobilização da caixa torácica - Foto: Claudia Mele

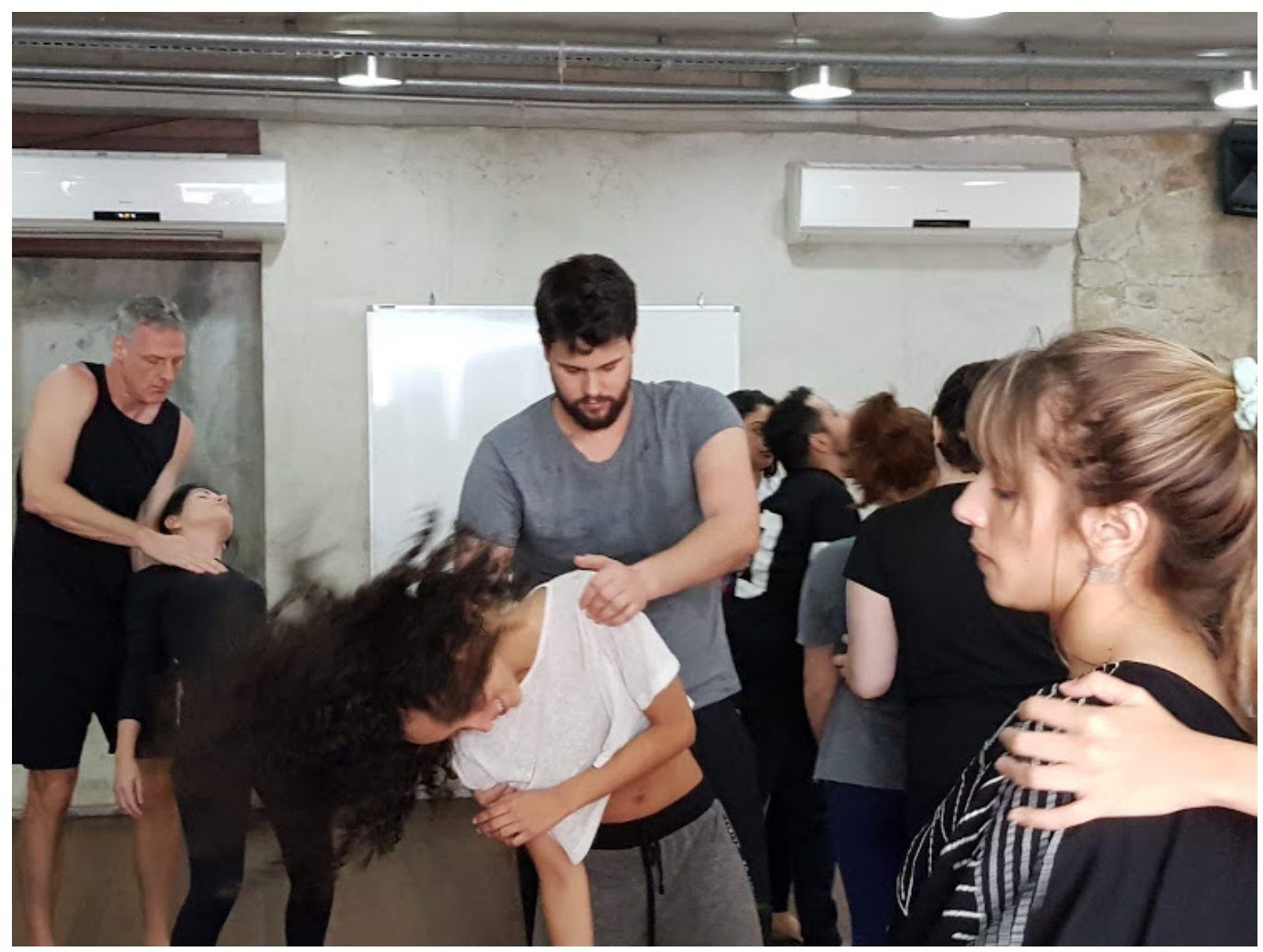

Os braços também ficaram muito mais fluidos depois da aula, com uma leveza diferente (Monique).

Fiz movimentos com o corpo, até à exaustão, que me deram um alívio no peito enorme (João).

Quando a Vitória regeu minha dança, eu pude livremente sentir paz em mim, confiança em me mover do jeito que meu coração e corpo mandavam, me sentindo confortável para experimentar aquilo que minha intuição puxasse para o movimento e assim eu fui (Alana).

Mandala com tempo 1 prolongado

O grupo em uníssono realiza quatro movimentos em tempos cadenciados: Tempo 1 - levantar na frente do corpo as duas mãos com as palmas para a frente; Tempo 2 - os braços se cruzam e descruzam na frente do abdômen uma vez; Tempo 3 - os braços se cruzam e descruzam outra vez; Tempo 4 - as mãos se juntam em prece. No segundo ciclo de repetição soma-se à 
sequência dar um passo para a direita no Tempo 2. Dinâmicas distintas são propostas, alternando os ciclos, uma vez com o passo e outra sem. Depois, formam-se duas rodas com o mesmo número de pessoas, uma dentro da outra. As/Os participantes que estão no círculo de dentro viram-se para os de fora. Repetem-se as mesmas sequências com as/os alunas/os focalizando os olhos da pessoa à frente. No primeiro movimento as mãos dos participantes se tocam, quando dão o passo para a direita trocam de dupla. Antes de repetir esta dinâmica, duplas intercaladas trocam de círculo para que pessoas diferentes possam se encontrar. A sequência de movimentos é alterada: no Tempo 1 troca-se um abraço (antes tocava-se as mãos da/o outra/o); nos Tempos 2 e 3 dá-se um passo à direita para sair do enlace corporal; e o Tempo 4 permanece o mesmo.

Foi tão bom receber aqueles abraços verdadeiramente amorosos e fortes. Me senti muito conectado com meus colegas, quando o tempo final da música ficava mais lento e os abraços se prolongavam (Daniel).

Figura 2 - Tempo 1 da música. Foto: Claudia Mele

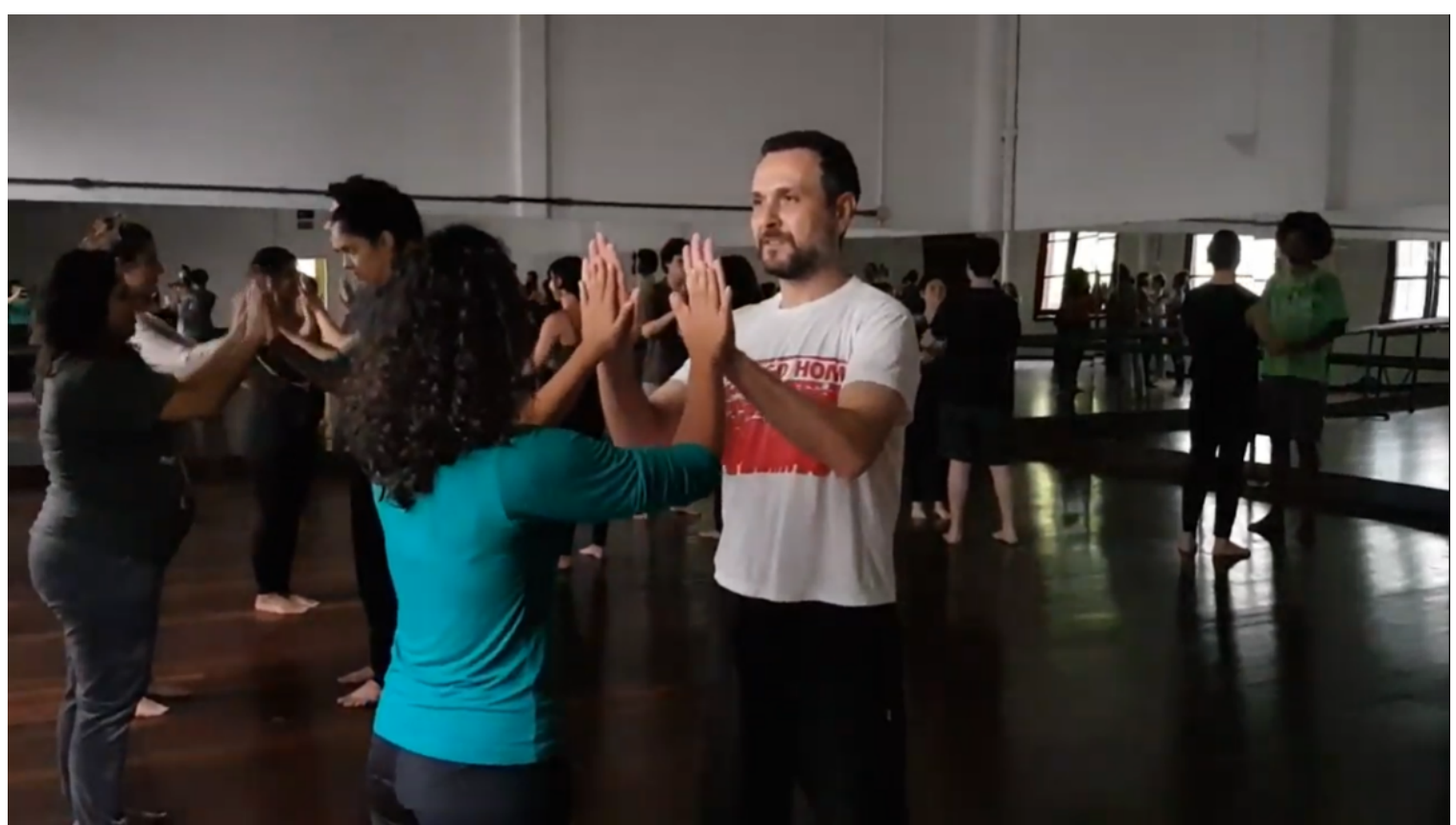




\section{Urdimento}

Esta série de exercícios foi proposta pelo preparador vocal Ernani Maletta nos processos de ensaio da peça Elis, Estrela do Brasil (2002) ${ }^{15}$, em que participei como atriz. Desde então, trouxe para as minhas turmas esta sequência de atividades, utilizando a mesma música, Haikai Pt.5 do UAKTI 21, sugerida por Maletta. Isto porque, no decorrer desta, o Tempo 1 vai aos poucos se estendendo, fazendo com que as/os alunas/os permaneçam mais tempo no contato visual, no toque da mão e no abraço (quando repetimos a música para a realização da segunda sequência).

Figura 3 - Na repetição da música, a ação do tempo 1 é o abraço. Foto: Claudia Mele

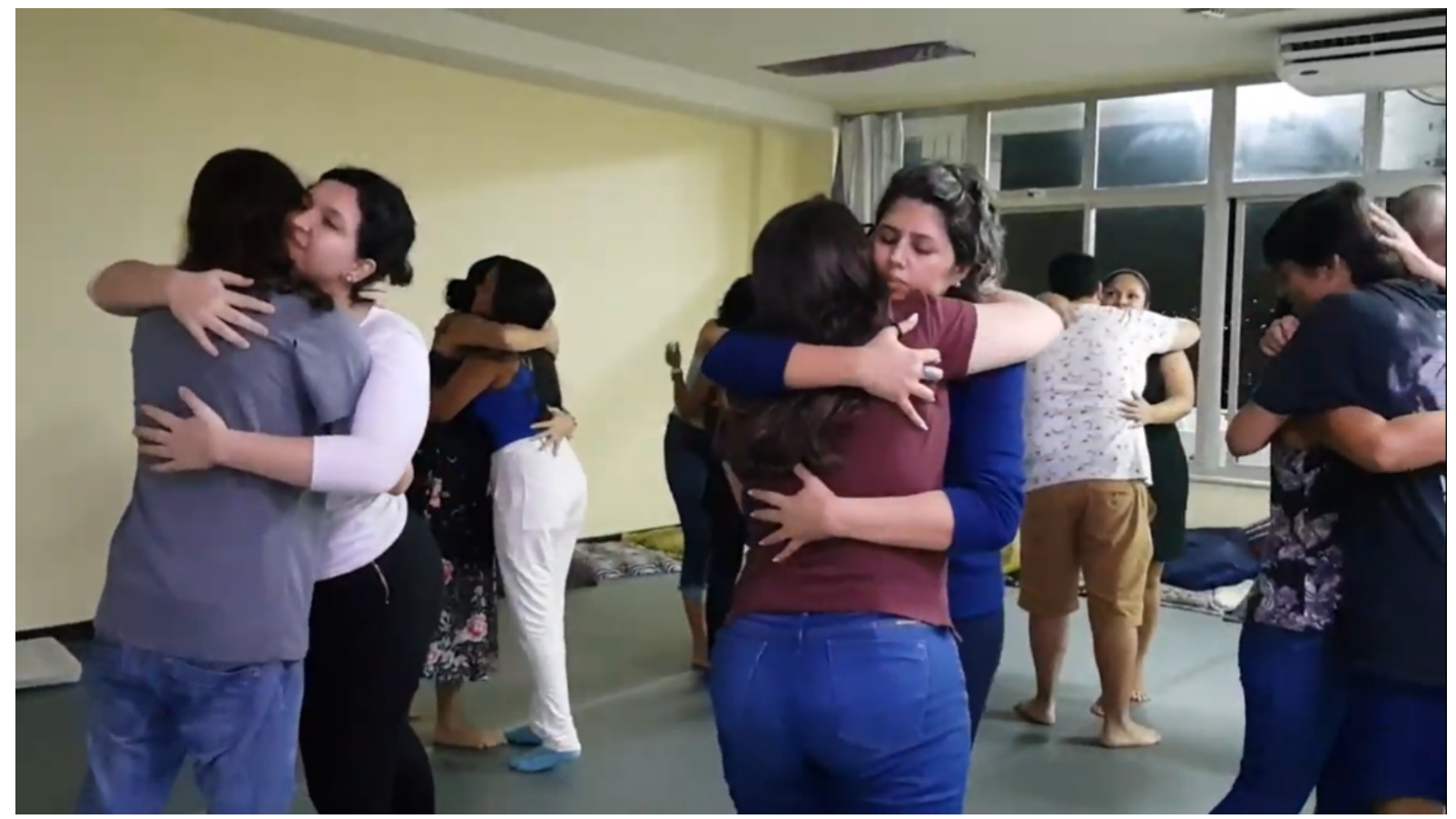

Aquela música, todo mundo junto e disponível. Ali, parar, olhar no olho da pessoa da nossa frente...Já trazia uma emoção muito forte! Não olhar por olhar, mas olhar e está de fato presente, entregue e observando o outro (Luiza).

A partir do chakra cardíaco nos abrimos para a compaixão e a coletividade. Este exercício nos proporciona o contato direto com a/o outra/o por meio do olhar, do abraço, da escuta da música e do grupo. Além disso, ele é realizado em dois 
círculos que formam uma mandala em movimento, a sensação de coletividade é bem presente.

Como o olhar e o abraço são fortes para mim. Eu gosto de abraçar os outros. Através do olhar e do abraço, percebi a intensidade de cada pessoa, quem estava "mais" aberto a se doar. Senti carinho de pessoas que praticamente não conheço. Dos que conhecia, alguns senti mais essa conexão. Mas até dos que senti menos doação de carinho, o abraço serviu para abrir uma porta para iniciar esse vínculo na turma (Juliana).

Ao realizarem este exercício, após soltar a caixa torácica e a cintura escapular, as/os alunas/os ficam bem sensíveis e afetuosas/os. Algumas/uns ficam receosas/os em abraçar verdadeiramente, não se entregam ao contato com a/o outra/o, o que demonstra a dificuldade em abrir o coração. Entretanto, outras/os se entregam profundamente, abraçando com todo o corpo.

Os braços são regidos pelo chakra do coração. Se ficarmos em pé com os braços estendidos ao lado, na altura do ombro, formamos uma cruz, cujo centro é o anahata. Este é o centro do sistema e os braços são sua extensão. Através do abraço demonstramos nosso afeto. Na medicina chinesa, os meridianos yin dos braços correspondem ao coração, pulmões e pericárdio, e se localizam na parte interna dos braços, com a qual tocamos as pessoas quando as abraçamos. Anodea Judith (2010) nomeia a extensão que vai do coração para as mãos como canais de cura. Quando abraçamos alguém, não só estimulamos estes meridianos, como tocamos com o nosso chakra do coração o anahata da/o outra/o. Um abraço pode ser extremamente curador, cura no sentido de permitir um reequilíbrio do sistema.

A cada pessoa que eu abraçava sentia vontade de sorrir (a maioria dos alunos também) e sentia uma energia boa vinda da maioria das pessoas. (Juliana).

Tenho uma confissão a fazer: não sou de abraços. Talvez pela minha timidez, não sei. Abraço muito a minha família, meu namorado, abraço pessoas da minha intimidade com muito prazer e felicidade, mas não consigo ser assim "na rua". [...] Numa atividade como essa não tenho muito para onde fugir e isso é bom. É bom porque percebo que não controlo nada. A vontade de chorar vem sem que eu queira, eu me pego abraçando e chorando e sendo abraçada de um jeito que, espontaneamente, eu não faria. Quando o "Tempo 1" da música demorava e o abraço se estendia, eu me pegava demorada em um abraço, que se 


\section{Urdimento}

fosse partir da minha vontade não aconteceria (Marcela).

Nos momentos de abraço, geralmente, muitas/os alunas/os já estão chorando. Ao chorar a pessoa pode intensificar um processo de desbloqueio e soltura da energia do chakra do coração.

Figura 4 - Abraços. Foto: Claudia Mele

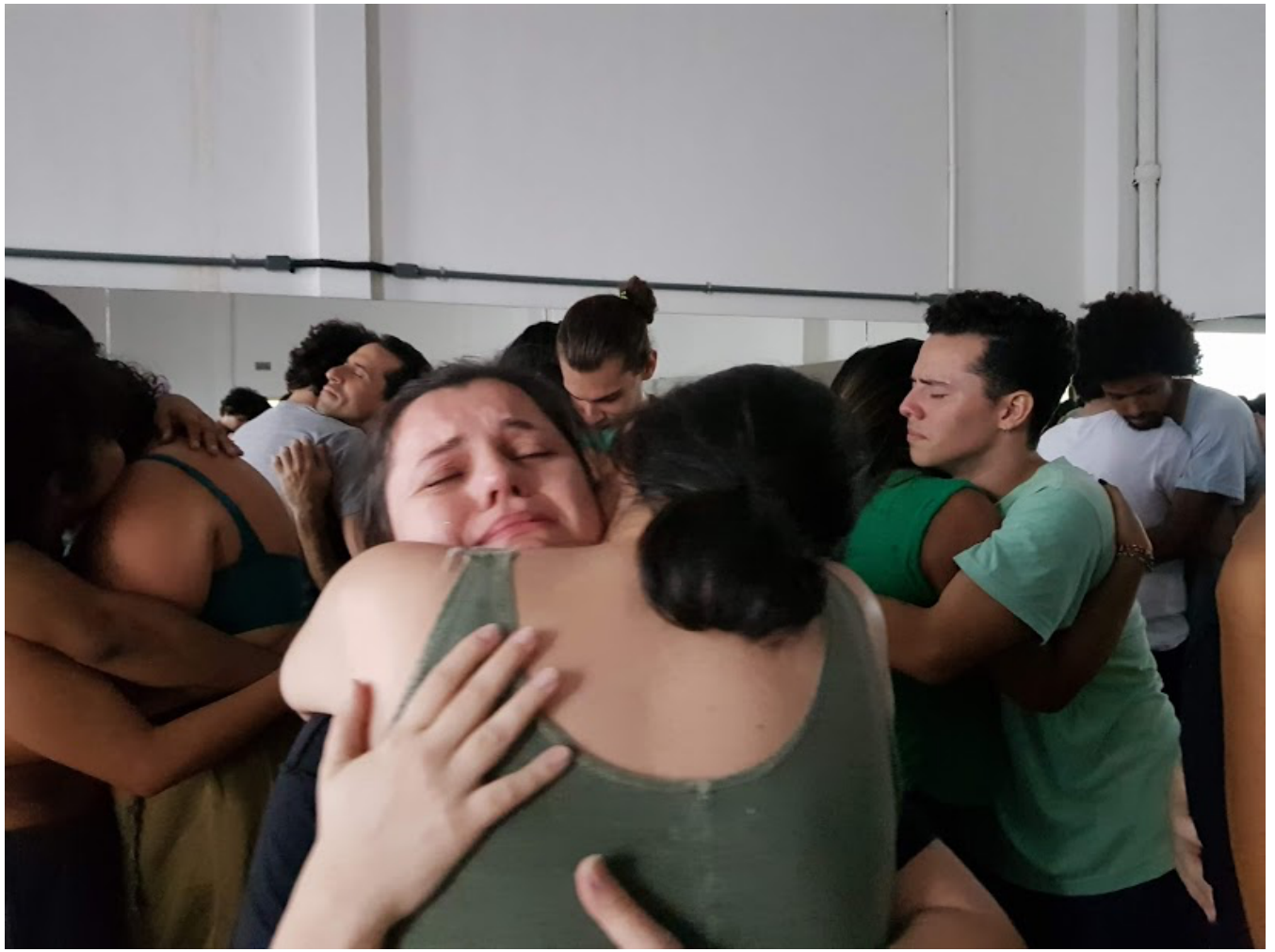

No meio da aula senti meu coração se abrindo e logo em seguida comecei a chorar (João).

Na primeira aula que tivemos do chakra do coração senti, ainda nos exercícios iniciais, alguma vontade de chorar. Infelizmente, sigo na luta entre o que o meu corpo propõe e o que os meus pensamentos julgam. Me segurei o quanto pude, porque critiquei o fato de chorar durante um exercício. Certamente, canais estavam sendo desbloqueados e eu vacilei, não deixando o meu corpo fluir como deveria (Marcela).

Também tenho observado nas aulas que algumas/uns alunas/os travam o choro com medo de se exporem. Ainda existe pudor em chorar e demonstrar 
amor. Me vem à lembrança agora o poema de Álvaro de Campos que brinca com a ideia de que todas as cartas de amor são ridículas. Acredito que esta ideia faz parte do nosso imaginário como uma forma de proteção, de defesa, pois chorar ou se abrir para o amor pode significar expor as nossas fragilidades. Assim, podemos parecer patéticos, palavra derivada de pathos, emoção. Contudo, como observa Didi-Huberman (2016, p. 19), esta fraqueza nada tem de ridículo: "Muito ao contrário! Quando se arrisca a 'perder a pose', esse ser exposto à emoção se compromete também com um ato de honestidade [...] há mesmo muita coragem nesse ato de mostrar sua emoção".

Existe uma herança histórica que age em nosso inconsciente, entendendo que o choro e a expressão das emoções devem ser reprimidos. Didi- Huberman (2016) observa que os filósofos clássicos, desde Platão a Kant, consideravam a emoção como uma fraqueza, um defeito, até mesmo uma impotência. A emoção se oporia à ação e à razão. "Kant, por exemplo, disse que a emoção é apenas um 'defeito da razão', 'uma impossibilidade de refletir'” (Didi-Huberman, 2016, p. 23). Darwin afirmava que chorar é um ato primitivo e que encontramos a emoção principalmente em crianças, mulheres (sobretudo as loucas), velhos (sobretudo os doentes mentais e senis) e nas "raças humanas que têm pouca semelhança com os europeus" (Darwin apud Didi- Huberman, 2016, p. 15). A idade da razão seria, então, a idade em que precisamos aprender a reprimir essa tendência primitiva de expressar as emoções. O cientista evolucionista britânico orgulhava-se: "O inglês não chora a não ser sob pressão da mais pungente dor moral" (Didi- Huberman, 2016, p. 16).

Todo esse pensamento construído durante séculos está presente em nós de forma estrutural. Além disso, tenho observado que é mais fácil mantermos o coração fechado, pois assim, a dor que o bloqueou não vem à tona. O que bloqueia o chakra do coração é o medo de sentir uma dor anteriormente experienciada. O que desbloqueia esta energia pode nos fazer entrar em contato novamente com esta dor.

Achei que não ia chorar, pois há uns cinco anos me sinto mais fechado emocionalmente para outras pessoas [...] na hora que ficamos em roda, inexplicavelmente, me senti extremamente emocionado. Algo que foi 
ficando cada vez mais intenso, lembrando de cada pessoa que me ama. E na hora que fui tentar balbuciar o que tinha a dizer, eu nitidamente estava muito emocionado, chorei com uma força que não fazia há muito tempo. Eu já imaginava que meu chakra estivesse bloqueado, pois o meu antigo relacionamento não foi legal, foi tóxico para mim, abusivo. Somado a isso, trabalhava com uma equipe tão tóxica quanto, acabei me fechando muito [...] acho que é natural esse fechar para o balanço (Raphael).

A entrega de cada turma para a experiência depende da disponibilidade de abertura das pessoas para o fluxo livre do coração, que muitas vezes se expressa pelo choro. Às vezes, o choro vem como se algo, que entendo como a energia do coração, estivesse sendo destravado. No início da aula, quando algumas/uns alunas/os se permitem chorar, observo durante a mesma que uma verdadeira catarse vai acontecendo, com o choro contaminando todo o grupo.

Ao final da aula, quando estava anotando as percepções do dia, comecei a chorar muito e sem parar. A cada registro vinham mais lágrimas e lembranças pessoais. Algumas pessoas me abraçaram. Permaneci na sala até que o meu corpo parasse de chorar (Juliana).

No início, me questionava se toda esta catarse poderia trazer para as/os alunas/os algum perigo, já que podemos entrar em contato com memórias de dor que revivem traumas. Mas, no decorrer da prática fui percebendo que tudo que é feito através do amor não pode causar danos e que pode, inclusive, curar traumas ${ }^{16}$. Como afirma Judith: “O amor é a suprema força de cura” (2010, p. 242).

\section{Meditação em roda de mãos dadas}

Visualizar o coração como um botão de rosa, cor de rosa, com muitas pétalas fechadas sobre si mesmo. Aos poucos abrir cada pétala liberando o cheiro da rosa, visualizando também uma luz rosa que se desprende da flor e se espalha por todo o corpo. Deixar que a luz se espalhe para além do corpo, atravessando as outras luzes do coração de cada um da roda até toda a sala

${ }^{16}$ No final do semestre proponho um exercício que denominei de Performance como Cura. Observo uma transformação muitas vezes profunda em cada um, e todo o ambiente é envolto em muito amor. Nestas experiências temos presenciado curas de traumas. Será o tema de um novo artigo. 
ficar inundada da luz rosa do amor. Levar esta luz para todo o bairro, cidade, estado, país e para toda a Terra.

Esta é uma meditação que pratico com muita frequência nas aulas. É ótima para a limpeza energética do ambiente, por exemplo. A luz do amor é poderosa para a mudança de frequência energética dos corpos e espaços. Desejar o amor para pessoas próximas e para toda a humanidade é uma prática que auxilia no exercício da compaixão. Gosto também de realizá-la antes do exercício que narro a seguir.

\section{Círculo do amor}

Uma/Um aluna/o entra no círculo formado pelo grupo. Todos pronunciam seu nome em voz baixa algumas vezes. Um por um verbaliza ou faz algum movimento ou gesto para a/o aluna/o que está no centro da roda, expressando o que aprecia nela/e ou a/o agradecendo por algo. Não valem críticas, comentários ou sugestões, apenas palavras positivas e amorosas.

Após ouvir as palavras e sentir os gestos expressos pelo grupo, a pessoa que está no centro agradece a si mesma por suas ações e qualidades.

Este exercício é sugerido por Anodea Judith (2010, p. 258) e é, sem dúvida, o exercício mais impactante que já experenciei com as/os alunas/os em todos estes anos como professora. Quando é realizado após as práticas descritas anteriormente, eles podem transformar profundamente a relação das/os alunas/os entre si, mudando o padrão de frequência da turma de forma poderosa. É muito difícil uma turma não se transformar após as aulas do chakra do coração e isto se deve principalmente a este exercício. Inúmeras vezes ministrei aulas para turmas consideradas "problema" que após as aulas do chakra cardíaco se transformavam.

Algumas vezes, quando as/os alunas/os estão com dificuldade em abrir o 
coração, apesar de terem vivenciado as práticas citadas anteriormente, o início do exercício fica um pouco travado com as pessoas ligeiramente constrangidas, como se não soubessem o que dizer. Mas, no decorrer da prática a energia vai se transformando e os corações vão se desbloqueando.

No momento em que a professora disse que teríamos que nos agradecer eu me desconectei do que estava acontecendo ali para ser tomada por um pequeno desespero e medo súbito. Eu tinha medo de ir pro meio da roda, tanto medo que não consegui pensar em mais nada a não ser 'meu Deus, o que vou dizer quando chegar a parte de me agradecer?’ ou então 'e se eu não chorar quando começarem a me agradecer?' A partir desse momento eu senti que me bloqueei completamente (Carol).

É muito recorrente o medo de entrar no círculo por achar que as pessoas não terão palavras ou gestos para agradecê-la/lo ou admirá-la/o, ou o medo de não conseguir agradecer a si própria/o, como no caso da Carol. Algumas/uns alunas/os adiam a entrada na roda por três aulas, porque este é um exercício que faço aos poucos, não realizo todo no mesmo dia para não ficar exaustivo.

A partir desse sentimento de "não-validez", comecei a temer muito a próxima aula, porque sabia que dessa vez eu não escaparia da roda. Dessa forma, eu comecei, inconscientemente e involuntariamente, a buscar qualquer motivo que conseguisse servir como uma desculpa convincente, até para mim mesma, para que eu faltasse à aula (Paula).

Em função de certa resistência interior, algumas/uns alunas/os faltam às aulas seguintes para não entrarem na roda. Outras/os se confundem e aparecem na sala achando que será a aula sobre o chakra laríngeo e se desesperam com a possibilidade de entrar na roda. As pessoas sofrem tanto pelo medo de não receber amor como de recebê-lo, contudo, todos acabam entrando na roda.

A minha experiência dentro da roda foi muito boa [...] Mas confesso que fiquei bem sem graça. Nunca soube lidar muito bem com muitos "elogios" [...]. Fiquei surpresa e refleti bastante durante a semana, porque também tive dificuldade em me agradecer! Parece que eu não tinha orgulho de nada em mim. Apesar disso, acho que soube lidar bem com essa percepção. Não me desesperei, porque eu enxergo que o problema não 
está na minha vida em si e na maneira que eu a levo e sim na maneira em que eu ando a enxergando (Luiza).

É presente a dificuldade em agradecer ou valorizar as qualidades de outrem. Testemunhei casos de alunas/os que não conseguiram falar absolutamente nada durante todo o exercício do círculo do amor, como foi o caso do João. Ele ficou tão impressionado com a própria dificuldade que dedicou o trabalho final do semestre ao chakra cardíaco. Escreveu uma carta de amor a si próprio, porque percebeu que o obstáculo que o impedia de dizer ao outro que o admirava vinha de uma profunda dificuldade de se reconhecer de forma amorosa. A escrita era muito afetuosa, enquanto lia em voz alta recebia as palavras como se as ouvisse pela primeira vez. Este trabalho ficou profundamente marcado na minha memória pelo estado de vulnerabilidade em que João se colocou. Foi de uma beleza indescritível. Quando nos rendemos baixamos nossas defesas e assim o coração se abre, entramos em contato com a nossa essência amorosa. A cura vem através do contato interior com esta essência.

No início foi apavorante estar tão vulnerável no meio das pessoas. Ouvir cada um agradecendo por coisas simples e pelo meu jeito de ser na vida foi ao mesmo tempo horrível e maravilhoso: horrível porque eu não conseguia acreditar em tudo aquilo que era dito. É muito difícil admitir certas coisas para mim mesmo e maravilhoso por sentir energias tão boas sendo transmitidas. Senti uma conexão forte vinda dos outros, uma sensibilidade grande, como se todos flutuassem de olhos fechados numa dança sem ritmo e sem formas, leves como o ar (Lucas).

Ao exercitar o amor, mudamos o nível de consciência e vemos o mundo e as pessoas a partir de outra perspectiva. Relembro David Hawkins (2002): uma única pessoa vibrando na frequência do amor pode afetar a Terra mais do que 700 mil indivíduos que vibram na raiva. Este exercício possui grande potência por ser feito em coletividade vibrando amorosidade, portanto afeta profundamente todas as pessoas que realizam a prática.

O chakra quatro é sobre esse resgate do amor sincero e expressivo como forma de mudar o mundo [...]. Para mim, especificamente, foi uma 
experiencia transformadora ouvir as coisas lindas que meus amigos falaram para mim, enquanto estava no centro da roda. As pessoas me agradeceram pela minha gentileza, pela minha luta política, pela minha amizade. Mas confesso que o que me deixou profundamente emocionado foi ouvir mais de um agradecimento por eu fazer rir e por alegrar as pessoas. É como se ali eu tivesse confirmado a importância do meu trabalho na comédia. $E$ isso também me fez refletir, durante as semanas seguintes ao exercício, o quanto eu dou e recebo afeto através do riso que eu gero e que me geram (Daniel).

Hawkins teve uma grave doença em certo período de sua vida e, quando acordou da inconsciência, ele sentia somente a "Presença Infinita" e não via nenhum propósito em estar aqui na Terra. Quando encontrou um propósito e voltou a trabalhar, com pacientes que haviam sido considerados incuráveis por outros médicos, ele percebeu como a energia amorosa é extremamente importante para a cura. Ele conta que sentia profundo amor por todos os seus pacientes. Para o psiquiatra, todas as pessoas eram esplendorosas, e ele percebia que toda a humanidade estava motivada pelo amor interior, mas não sabia como acessá-lo. As pessoas pareciam dormir e não querer, ou não saber, despertar a consciência para o que realmente eram. Hawkins atendia pacientes de todo o mundo com problemas de saúde gravíssimos, sem nenhuma esperança, mas via claramente em cada um deles a essência do amor. Entendeu que apenas precisava ajudá-los a despertar a essência do amor, já contida neles.

O mais lindo foi perceber cada um agradecendo a si mesmo. Era fato que eu sempre chorava nessa hora, pois não é fácil admitir que você é bom consigo mesmo, que diariamente suas atitudes são importantes para construir quem você é. É mais fácil se cobrar e se julgar a todo tempo (Lucas).

Durante um bom tempo acreditei que seria uma melhor professora se eu apontasse os problemas no processo da/o aluna/o, pois assim ela/e poderia resolver as questões e realizar melhor o seu trabalho. Hoje vejo o quanto é mais importante realçar suas qualidades, seus méritos, o que gerou em seu corpo acontecimentos, desta forma tenho diminuído as críticas. Consequentemente, tenho observado um crescimento exponencial na expressividade das/os alunas/os.

Por esse motivo fui transformando o trabalho com o chakra cardíaco em um 
movimento de autoconhecimento, diminuindo cada vez mais a preocupação com os resultados artísticos. Entendi que antes de tudo a/o aluna/o precisa conhecer, confiar e amar a si mesma/o para realizar processos artísticos mais potentes. Ou melhor, aprendendo a se amar, a/o aluna/o descobre a potência de sua arte.

Julgamo-nos demais, frequentemente uma crítica acaba bloqueando o processo da/o aluna/o e ela/e vai perdendo a fluidez e a entrega. A experiência nas aulas do chakra cardíaco, especialmente nesse exercício, me conduziram a esta compreensão. Contudo, gostaria de ressaltar que isso depende da personalidade de cada aluna/o e da situação em si. Alguns precisam receber críticas, mas a maioria responde melhor quando valorizamos suas potências. Com amorosidade, as/os alunas/os tomam consciência de suas questões sem precisarmos apontálas.

Tive mais consciência das minhas ações e dos meus mecanismos e acredito que isso possa ser até mais importante do que ter conseguido enfrentar os medos de primeira. Há bloqueios tão enraizados dentro de mim que simplesmente seria impossível conseguir quebrá-los agora, mas sei o quão importante é eu estar podendo ter mais consciência das minhas ações para que futuramente eu possa de fato quebrá-los (Carol).

Algumas vezes, antes de começarmos os exercícios, peço que as/os alunas/os fiquem em círculo e sugiro que três ou quatro escolham um texto decorado e o falem olhando no olho de cada integrante da roda. No final da aula, após a realização dos exercícios de soltura da região do chakra cardíaco, dos abraços e do exercício do círculo do amor, peço que falem novamente os textos para o grupo. É realmente impressionante a expressividade das/os atrizes/atores nesse momento e a diferença entre a primeira e a segunda performance, visto que, após as vivências, elas/eles se apropriam do que dizem, expressando com o coração as palavras. Acredito que a ideia de verdade cênica tem relação direta com a capacidade de acessar a energia deste chakra. Quanto maior for a abertura do chakra cardíaco mais a/o atriz/ator será verdadeira/o em cena para se relacionar com o outro e para sentir profundamente o que está sendo expresso. Fay Simpson (2012), diretora norte-americana e criadora da técnica Lucidy Body, afirma que o trabalho da/o atriz/ator é amar. 
Menciono no início do artigo que muitas foram as pequenas revoluções vividas a partir destas aulas. Vi alunas/os se transformarem vividamente e turmas inteiras criarem novas formas de relacionamento entre si. Tive algumas turmas consideradas problemáticas e ainda fico impressionada com a mudança de energia ocorrida já na primeira aula. As/Os alunas/os cooperam mais umas/uns com as/os outras/os, tornando-se mais participativas/os nas tarefas coletivas, colocando-se mais no lugar da escuta.

Os desbloqueios das articulações e liberação do fluxo de movimento proporcionado pelos exercícios colabora para o desenvolvimento de um corpo mais poroso e criativo, ou seja, para uma expansão corporal. A prática da amorosidade auxilia no desbloqueio de tensões e na mudança de padrões, permitindo a abertura para os corpos espirituais ligados à intuição e à criatividade. Ao dinamizar e aumentar os trânsitos energéticos do anahata, libera-se a ponte entre os corpos mais densos, ligados à materialidade e os corpos sutis, ligados à espiritualidade. Isso resulta no aumento da criatividade e da qualidade das ações que se tornam mais orgânicas e verdadeiras ${ }^{17}$. No segundo módulo, o trabalho com as ações físicas e construção de personagens se torna fluido, porque as/os alunas/os estão mais abertas/os aos impulsos criativos e intuitivos que atravessam todo o seu corpo.

Agora precisamos aguardar a vacina contra a Covid-19 para que possamos voltar a nos abraçar. Fiquei apreensiva com a transposição das aulas do chakra do coração para as plataformas digitais durante a pandemia. Claro que tive que adaptar muitos exercícios, mas pude constatar que mesmo virtualmente o trabalho tem sua potência. A força do amor sempre se mostra presente. Nas práticas on-line, propus exercícios meditativos de cuidado e amor para si mesma/o por meio do autotoque, uma maneira de substituir os abraços. Continuei com a roda de cura, mas esse exercício não atingiu a mesma intensidade das aulas presenciais em função do distanciamento físico. As alterações realizadas no decorrer deste período serão tema de um novo artigo.

${ }^{17}$ No sentido de mais próxima da verdade de cada um/a. 
Concluo este texto contando a história de Henrique, meu aluno no primeiro semestre de 2016. Naquele período ainda se chamava Agnes. Saiu de Recife dois anos antes para fazer teatro no Rio de Janeiro. Estava se descobrindo lésbica. Durante o processo de aulas, observei uma grande mudança nele. Eu e a turma vimos seu coração desabrochar de uma forma muito bela. Continuamos amigos até hoje e pedi que escrevesse um texto sobre a sua experiência com o chakra do coração para o presente artigo. Selecionei alguns trechos do seu texto de sete páginas. Henrique conta que quando iniciaram as aulas "sofria de amor": "Não falo de amores afetivos sexuais conjugais não correspondidos... falo de amor-próprio não correspondido. Quando você se ama (ou nem isso), mas você mesmo não

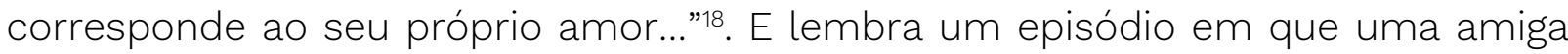
veio the abraçar e recuou dizendo: "Não gosto que me toquem, não gosto de abraço, contato demais, desnecessário, o que você precisa falar pode falar daí". No primeiro dia de aula escreveu em seu diário ${ }^{19}$ :

Nunca vi isso, sair distribuindo amor aleatoriamente por aí [...] $]^{20}$. É óbvio que eu amo, mas não amo qualquer um, aliás, acho bem 'não-amor' essa forma banal de sair sorrindo por aí e cumprimentado até as plantas. [...] A minha turma nunca foi assim, todo mundo sempre se odiou e se xingou, sempre foi cheio de intriga e picuinha....

Realmente era uma turma grande e cheia de pequenos grupos que se comunicavam pouco uns com os outros. Uma turma muito talentosa, mas que se perdia entre tantas desavenças. Durante o exercício do círculo do amor, foi uma verdadeira catarse, pessoas que não se falavam pediram desculpas e tiveram a oportunidade de trocar afetos. Ao final da primeira aula do chakra cardíaco, Henrique/Agnes teve vontade de vomitar. "É como se meu corpo não suportasse, algo ia ter que sair para esse amor entrar. Escolhi a raiva, fiquei com a amargura, parecia mais fácil lidar com o que eu já tinha lidado a vida inteira”. Henrique/Agnes teve vontade de faltar à segunda aula, contudo foi por orgulho: "Que imagem eu

\footnotetext{
18 Todas as citações a seguir são do texto de Henrique/Agnes.

${ }^{19}$ Os trechos do diário, que estão em fonte 11, também estão inseridos no texto enviado por Henrique.

${ }^{20}$ Cortes feitos por mim.
} 
passaria ao fugir do amor?”. Ele menciona que a segunda semana foi diferente, no seu diário dos chakras estava escrito:

\begin{abstract}
Nessa última semana, a turma tem estado bem diferente, as pessoas 'mudaram', estão mais pacíficas, foi uma semana bonita e gostosa de se viver aqui na turma pela primeira vez em MUITO tempo. [...]. ${ }^{21}$ Confesso que ainda acho um pouco estranho processar tudo que foi dito, eu realmente não entendo. [...] confesso que também me surpreendi com as coisas que me peguei dizendo, não eram mentiras, mas eu realmente não tinha ideia de que achava tudo isso. Aproveitei o dia para falar com outras pessoas de fora da faculdade, foi leve, me senti bem à noite, não sei, parecia que tinha mais espaço pro ar passar dentro de mim.
\end{abstract}

Sabemos o quanto é mais fácil julgar, nos acostumamos com o exercício do julgamento e achamos que não precisamos dizer o que admiramos no outro. 0 exercício do amor exige treino. Esta constatação de Henrique observei em muita/os outras/os alunas/os durante as aulas sobre este chakra. Na terceira aula, a raiva de Henrique que ainda estava latente se transformou em pânico, medo de entrar na roda e descobrir que não existia nada de amoroso a ser dito sobre ele "medo de entrar e perceber que eu era um lixo [...]. Nunca foi tão gostoso estar completamente errado".

A turma está mais unida. Antes muitas pessoas vinham falar comigo que não iam fazer a formatura porque não aguentavam mais. Mas agora decidiram que vão sim. Hoje não consegui escapar, tive que ir para roda. Ouvi coisas que nem imaginava, coisas boas, mas não sei por que foi desesperador, apesar de serem coisas boas, não sei, não me senti muito confortável, na verdade, percebi o quanto me afastei das pessoas que eram tão próximas [...] isso fez eu me sentir mal, questionar o que eu venho fazendo, como trato meus amigos, minha família, minha mãe, as pessoas a minha volta, meus não amigos. Falaram coisas MUITO boas de mim, mas eu sou uma boa pessoa? Desde quando? Eu nunca fiz mais do que o normal para essas pessoas, não entendo por que esses elogios e agradecimentos [...]. Estando na turma à noite fazendo assistência [de direção] eu consigo perceber a diferença que faz uma aula de chakra. A energia da noite é muito pesada, me estressa, me consome. Quando chego na minha turma de manhã é como se nada estivesse acontecendo na minha vida exterior. O lugar que mais me trazia problemas, estresses e me sugava tem sido um dos lugares mais gostosos de se estar nos últimos dias. Isso é bom.

${ }^{21}$ Cortes feitos por Henrique. 
No decorrer das aulas seguintes, Henrique foi se aproximando de mim. Sempre brincava dizendo que não queria saber sobre aquele chakra quatro. Expressava isso de forma carinhosa num movimento claro de abertura do coração. $\mathrm{Na}$ época, ele tinha 23 anos e era bonito ver sua transformação a cada dia. Hoje ele diz que o desabrochar de seu coração permitiu que se acolhesse como um homem trans e que olhando para trás se surpreende como pôde "construir um muro com medo da invasão das flores".

“Abrir o chakra quatro me permitiu o perdão à minha mãe biológica, o perdão a mim mesmo, me permitiu enxergar inclusive o que era tão óbvio em mim... uma masculinidade, até então tóxica, oprimida e opressora de minha própria feminilidade". A transição começou silenciosa, alguns meses após o término da disciplina e se concretiza hoje, quatro anos depois, com alteração de seus documentos.

Como esta conclusão é quase toda de palavras do Henrique deixo que ele finalize: "Não existe mais espaço para um mundo que não tem espaço para o Amor. Então, a gente escolhe: ou abrimos espaço para isso, ou o espaço se abrirá, sem força, sem briga, afinal é amor e ele é folgado, espaçoso, do melhor jeitinho e único de amar".

\section{Referências}

BRENNAN, Bárbara Ann. Cura pela luz interior. conceitos avançados de cura para ter uma vida plena. São Paulo: Pensamento, 2018.

DIDI-HUBERMAN. Que emoção! Que emoção? São Paulo: Editora 34, 2016.

HAWKINS, David R. El Poder contra la Fuerza: los determinantes ocultos del comportamento humano. Carlsbad, California: Hay House, 2002.

HOOKS, Bell. Outlaw Culture: resisting representations. New York: Routledge, 2006.

JUDITH, Anodea. Rodas da Vida: um guia para você entender o Sistema de Chacras. Rio de Janeiro: Nova Era, 2010.

PEIRCE, Joseph Chilton. The Biology of Transcendence: A Blueprint of the Human Spirit. Rochester: Inner Traditions Bear and Company, 2004. 
RAMACHARAKA, Yogi [William Walker Atkinson]. Hatha Yoga: The Yogi Philosophy of Physical Well-being. Chicago: The Yogi Publication Society, 1904.

SIMPSON, Fay. The Lucid Body. a guide for the Physical Actor. New York: Allworth Press, 2012.

VÁSSINA, Elena, LABAKI, Aimar. Stanislávski: vida, obra e Sistema. Rio de Janeiro: Funarte, 2015.

WALLACE, B. Alan. Felicidade Genuína: Meditação como o caminho para a realização. Teresópolis: Lúcida Letra, 2015.

Recebido em: 11/01/2021

Aprovado em: 19/04/2021 